\title{
Prevalence, Awareness and Control of High Blood Pressure in a Semi-Urban Area of Cameroon: An Analysis of May Measurement Month 2019 Screening Results
}

\author{
Dieudonne Danwe ${ }^{1}$, Sylvie Ndongo Amougou ${ }^{2 *}$, Alida Tchamba Choumi ${ }^{1}$, \\ Christian Ngongang Ouankou ${ }^{2}$, Lionel Armel Bala ${ }^{1}$, Patrick Soume Adala ${ }^{1}$, Daniel Lemogoum ${ }^{3}$ \\ ${ }^{1}$ Diabetes and Hypertension Clinic, Mbalmayo District Hospital, Mbalmayo, Cameroon \\ ${ }^{2}$ Cameroon Cardiac Society, Yaoundé, Cameroon \\ ${ }^{3}$ Cameroon Heart Foundation, Douala, Cameroon \\ Email: *ndongoamougou@yahoo.fr
}

How to cite this paper: Danwe, D., Amougou, S.N., Choumi, A.T., Ouankou, C.N., Bala, L.A., Adala, P.S. and Lemogoum, D. (2019) Prevalence, Awareness and Control of High Blood Pressure in a Semi-Urban Area of Cameroon: An Analysis of May Measurement Month 2019 Screening Results. Open Access Library Journal, 6: e5955. https://doi.org/10.4236/oalib.1105955

Received: November 25, 2019

Accepted: December 20, 2019

Published: December 23, 2019

Copyright () 2019 by author(s) and Open Access Library Inc.

This work is licensed under the Creative Commons Attribution International License (CC BY 4.0).

http://creativecommons.org/licenses/by/4.0/

\section{(c) (i) Open Access}

\begin{abstract}
Background: High blood pressure (HBP) is a global health crisis. More than one billion people in the world suffer from HBP and most of them live in low and middle income countries where the prevalence is increasing. Unawareness, low treatment and control rates are the main barriers to the fight against this disease and the associated cardiovascular disease risk. Aims: To highlight the importance of measuring blood pressure and identify and reduce the blood pressure (BP) of those who require an intervention to lower their BP according to current guidelines. Methods: This was a cross-sectional study. A HBP screening was organized in two market places and at the district hospital of a semi-urban area in Cameroon during three days-from the $28^{\text {th }}$ to the $30^{\text {th }}$ May 2019. We included all people aged at least 18 years and who accepted to take part to the study. We used a predesigned form and electronic blood pressure machines for the screening. HBP was defined as having a $\mathrm{BP} \geq$ $140 / 90 \mathrm{mmHg}$ or taking antihypertensive medications. All statistical analysis were done using IBM SPSS version 20.0. Results: We included 200 people in the study. Women were more represented in our sample (57.5\%) and the median age was 40 years [30 - 51]. More than a third of the participants had not taken their BP in the past year and $16 \%$ of them had never measured their BP. HBP was detected in 49 (24.5\%) people among whom 25 (51.0\%) were aware of their condition. Among those who were aware they had HBP, 17 (68.0\%) were taking antihypertensive medications and as a single drug regimen in most cases (64.7\%). BP was controlled in 9/17 (52.9\%) people. Conclusion: Nearly one quarter of people living in semi-urban area in Cameroon has
\end{abstract}


HBP. We have found in this area a high rate of unawareness and undertreatment of HBP.

\section{Subject Areas}

Cardiology

\section{Keywords}

Prevalence, Awareness, High Blood Pressure, Semi-Urban, Cameroon

\section{Introduction}

High blood pressure (HBP) is a health crisis worldwide. Mills et al. estimated that 1.39 billion people had high blood pressure in the world, 349 million in high income countries and 1.04 billion in low and middle income countries [1]. Low awareness, treatment and control rates are the main obstacles to the fight against hypertension and associated cardiovascular disease risk, especially in low and middle income countries [2]. The International Society of Hypertension (ISH) therefore initiated since 2017 a global campaign of high blood pressure screening named May Measurement Month (MMM) in order to improve the world's health through raised awareness around blood pressure (BP). Analysis of the worldwide results of the MMM 2018 reported a hypertension prevalence of $33.4 \%$ of whom $59.5 \%$ were aware of their diagnosis and $55.3 \%$ were taking anti-hypertensive medication. Still the same year, $60 \%$ of those on antihypertensive medication hand their BP were controlled [3]. In comparison, the prevalence of hypertension was higher in 2017 (34.9\%) and there was a lower rate of BP control (53.7\%) [4]. The MMM 2017 in Cameroon revealed a prevalence of hypertension of $29.2 \%$ of whom $19.8 \%$ were not taking anti-hypertensive medication and 57.2\% had uncontrolled BP [5]. This year again, Cameroon took part in the MMM 2019 and we had a screening site in the town of Mbalmayo, a semi urban area situated at approximately 50 kilometers from Yaoundé, the Capital city. We analyzed the screening results at the local level in order to obtain site specific trends of hypertension, so we may adapt our policies concerning hypertension treatment and prevention in this area.

\section{Methods}

\subsection{Aims}

To highlight the importance of measuring blood pressure and identify and reduce the BPs of those who require an intervention to lower their BP according to current guidelines.

\subsection{Screening Setting and Duration}

MMM in Cameroon was coordinated by the Cameroon Cardiac Society (CCS), 
the Clinical Research Education, Networking and Consultancy (CRENC), a not for profit research organization, and Fondation Coeur et Vie (FoCev). In Mbalmayo, the diabetes and hypertension clinic of the Mbalmayo District Hospital was responsible for the screening sites. The staff of the clinic was made of one cardiologist, three general practitioners and three nurses. There were also some volunteers who took part in the screening campaign. The last was done in two market places and in the Mbalmayo District Hospital during 3 days.

\subsection{Inclusion Criteria}

All people aged $\geq 18$ years and who gave consent for participation where included in the study.

\subsection{Procedure}

1) Data collection was done using a screening sheet available has an appendix of this article.

2) We started by providing information about the study and collecting consent for participation. The following data were collected on all screenees: Date of measurement, age, sex, at least 1 SBP, DBP and heart rate.

3) BP measurements: BP was measured on the left upper-arm by an automated electronic device of the $\mathrm{OMRON}^{\circledR}$ or MAGNIEN ${ }^{\circledR}$ brands and ensuring that the correct size of arm cuff is used. The cuff was placed at the heart level and the patient's arm was resting comfortably on a table.

4) Prior to measurement:

- The participant was seated with their backs supported and with their legs resting on the ground and in the uncrossed position for $5 \mathrm{~min}$.

- The participants had not smoked immediately before or during the measurement.

5) One to three BP readings were taken and recorded with 1 min between readings.

6) For each BP reading, the automated BP devices also provided data on heart rate, and this information was also captured.

7) Data collected on each participant were recorded and submitted into the database via the MMM app (produced by Clarifi Media).

8) Definition of hypertension:

- being on at least one antihypertensive medication taken for raised BP or;

- the average SBP (mean of the last 2 of 3 readings) $\geq 140 \mathrm{mmHg}$ and/or;

- the average DBP (mean of the last 2 of 3 readings) $\geq 90 \mathrm{mmHg}$.

\subsection{Statistical Analysis}

Data collected at the Mbalmayo screening sites were analyzed using IBM SPSS Statistics software version 20.0. Analysises done were:

- prevalence of hypertension and its risk factors;

- prevalence of previously undiagnosed hypertension; 
- prevalence of antihypertensive medication use;

- prevalence of uncontrolled hypertension.

\subsection{Ethical Considerations}

All participants gave an informed consent prior to their inclusion in this study. Confidentiality was fully observed during the management of the data collected.

\section{Results}

We included 200 people in this study. Women were more represented with a percentage of $57.5 \%$. Table 1 shows the clinical characteristics of our study population. The median age was 40 [30 - 51] years. All but one of the participants were from black African ethnicity. Nearly half of them (48.5\%) had taken their BP less than 12 month before, meanwhile $16.0 \%$ had never taken their BP. Forty-nine $(24,5 \%)$ people had hypertension, among whom $25(51,0 \%)$ were aware of their disease. Of those who were known hypertensive, 17 (68.0\%) were taking anti-hypertensive medications, $11(64.7 \%)$ on single drug regimen, 3 (17.6\%) on two drugs regimen, 1 (5.9\%) on three drugs regimen and $2(11.8 \%)$ didn't know how many drugs they were taking. Hypertension was controlled in 9/17 (52.9\%) people. Table 2 demonstrates the prevalence of other cardiovascular risk factors found in our sample.

\section{Discussion}

This study was done using data obtained during a screening campaign organized

Table 1. Clinical characteristics of the study population.

\begin{tabular}{cccc}
\hline & $\begin{array}{c}\text { Men (n=85) } \\
\text { m (IQR) }\end{array}$ & $\begin{array}{c}\text { Women (115) } \\
\text { m (IQR) }\end{array}$ & $\begin{array}{c}\text { Total (200) } \\
\text { m (IQR) }\end{array}$ \\
\hline Age (years) & $39(26-50)$ & $42(32-52)$ & $40(30-51)$ \\
Weight (Kg) & $72(65-83)$ & $75(65-88)$ & $74(65-85)$ \\
BSA (Kg/m $\left.{ }^{2}\right)$ & $24.80(22.99-27.5)$ & $28.04(23.74-33.53)$ & $26.26(23.56-31.21)$ \\
PAS (mmHg) & $125(116-133)$ & $117(110-130)$ & $121(111-131)$ \\
PAD (mmHg) & $79(71-86)$ & $79(73-86)$ & $79(72-86)$ \\
FC (bpm) & $76(66-81)$ & $81(74-88)$ & $78(70-86)$ \\
\hline
\end{tabular}

Table 2. Prevalence of other cardiovascular risk factors

\begin{tabular}{ccc}
\hline Risk factors & Number & Percentage (\%) \\
\hline Obesity & 62 & 31.0 \\
Diabetes & 9 & 4.5 \\
Smoking & 25 & 12.5 \\
Alcohol consumption at least once a week & 83 & 41.5 \\
Past history of stroke & 2 & 1.0 \\
Past history of gestational hypertension/preeclampsia & 8 & 4.0
\end{tabular}


in a semi-urban area in Cameroon as a part of the global May Measurement Month 2019 (MMM19) campaign initiated by the International Society of Hypertension (ISH). We focused here on the specificity of the semi-urban area of Mbalmayo in the Centre region of Cameroon. The HBP prevalence in this study was lower than the $29.2 \%$ found by Dzudie et al. in 2017 and $29.7 \%$ found by Kingue et al. in urban area in 2015 [5] [6]. It was commonly thought than there was a urban-rural gradient of hypertension prevalence, but some observational studies show that the prevalence of HBP may be equal in urban and rural areas or even higher in rural areas depending on the country and region [7] [8] [9]. Arrey et al. found a higher prevalence of $31.1 \%$ in a rural area of Cameroon [10]. Similar studies need to be done in other semi-urban areas of the country to determine if this is not a site specific finding. The awareness rate we found was far higher than the results of other studies done both in urban or rural areas of Cameroon [6] [10] [11]. The other studies were community based with a multi-stage sampling method. For this screening, advertisement was used to invite people. Therefore, people having HBP or who thought they may have it were more likely to go to the screening points. However, the lower prevalence of hypertension in our study compared to the others contradicts this explanation. We also found in this study a greater percentage of people on anti-hypertensive medication and a higher control rate compared to the other areas despite the fact that it remains low [5] [10] [11]. Most of the patients on anti-hypertensive drugs were taking a single drug class. This does not correspond to the new European Society of Cardiology and the European Society of Hypertension 2018 guidelines for the management of hypertension which recommend a dual combination as initial therapy in most patients [12]. This low application of the guidelines is surely responsible for the low control rate we have and we need to correct it.

\section{Conclusion}

Nearly one person on four has hypertension in the Mbalmayo area. Half of the people having hypertension are aware of their condition and most of them are under treatment. There is a low control rate and the new hypertension treatment guidelines are not well applied.

\section{Authors' Contribution}

DD and SNA designed the study; DD, PSA, ATC and LAB collected the data. DD and CNO did the statistical analysis; DD, SNA and CNO drafted the manuscript; DD, ATC, CNO and SNA did the discussion and manuscript revision.

\section{Acknowledgements}

We address our thanks to the International Society of Hypertension (ISH), the Clinical Research Education Networking and Consultancy (CRENC), Denk Pharma and all the volunteers who participated in the screening. 


\section{Conflicts of Interest}

The authors declare no competing interest.

\section{References}

[1] Mills, K.T., Bundy, J.D., Kelly, T.N., Reed, J.E., Kearney, P.M., Reynolds, K., et al. (2016) Global Disparities of Hypertension Prevalence and Control: A Systematic Analysis of Population-Based Studies from 90 Countries. Circulation, 134, 441-450. https://doi.org/10.1161/CIRCULATIONAHA.115.018912

[2] Bloch, M.J. (2016) Worldwide Prevalence of Hypertension Exceeds 1.3 Billion. Journal of the American Society of Hypertension, 10, 753-754. https://doi.org/10.1016/j.jash.2016.08.006

[3] Beaney, T., Burrell, L.M., Castillo, R.R., Charchar, F.J., Cro, S., Damasceno, A., et al. (2019) May Measurement Month 2018: A Pragmatic Global Screening Campaign to Raise Awareness of Blood Pressure by the International Society of Hypertension. European Heart Journal, 40, 2006-2017. https://doi.org/10.1093/eurheartj/ehz373

[4] Beaney, T., Schutte, A.E., Tomaszewski, M., Ariti, C., Burrell, L.M., Castillo, R.R., et al. (2018) May Measurement Month 2017: An Analysis of Blood Pressure Screening Results Worldwide. The Lancet Global Health, 6, e736-e743.

[5] Dzudie, A., Djomou, A., Ba, H., Njume, E., Ndom, M.S., Mfekeu, L.K., et al. MMM17-Cameroon, Analysis and Opportunities-Sub-Saharan Africa. European Heart Journal Supplements, 21, D31-D33. https://doi.org/10.1093/eurheartj/suz081

[6] Kingue, S., Ngoe, C.N., Menanga, A.P., Jingi, A.M., Noubiap, J.J.N., Fesuh, B., et al. (2015) Prevalence and Risk Factors of Hypertension in Urban Areas of Cameroon: A Nationwide Population-Based Cross-Sectional Study. The Journal of Clinical Hypertension, 17, 819-824. https://doi.org/10.1111/jch.12604

[7] Rush, K.L., Goma, F.M., Barker, J.A., Ollivier, R.A., Ferrier, M.S. and Singini, D. (2018) Hypertension Prevalence and Risk Factors in Rural and Urban Zambian Adults in Western Province: A Cross-Sectional Study. The Pan African Medical Journal, 30, 97. https://doi.org/10.11604/pamj.2018.30.97.14717

[8] Adediran, S.O., Okpara, C.I., Adeniyi, S.O. and Jimoh, K.A. (2013) Hypertension Prevalence in an Urban and Rural area of Nigeria. Journal of Medicine and Medical Sciences, 4, 149-54.

[9] Giday, A. and Tadesse, B. (2011) Prevalence and Determinants of Hypertension in Rural and Urban Areas of Southern Ethiopia. Ethiopian Medical Journal, 49, 139-147.

[10] Arrey, W.T., Dimala, C.A., Atashili, J., Mbuagbaw, J. and Monekosso, G.L. (2016) Hypertension, an Emerging Problem in Rural Cameroon: Prevalence, Risk Factors, and Control. International Journal of Hypertension, 2016, 1-6. https://doi.org/10.1155/2016/5639146

[11] Lemogoum, D., Van de Borne, P., Lele, C.E.B., Damasceno, A., Ngatchou, W., Amta, P., et al. (2018) Prevalence, Awareness, Treatment, and Control of Hypertension among Rural and Urban Dwellers of the Far North Region of Cameroon. Journal of Hypertension, 36, 159-168. https://doi.org/10.1097/HJH.0000000000001513

[12] Williams, B., Mancia, G., Spiering, W., Agabiti Rosei, E., Azizi, M., Burnier, M., et al. (2018) ESC/ESH Guidelines for the Management of Arterial Hypertension. European Heart Journal, 39, 3021-3104. 